\title{
Utilidad de las pruebas de detección de antígeno urinario para un diagnóstico rápido de legionelosis
}

\section{Usefulness of urinary antigen detection tests for a rapid diagnosis of legionellosis}

Correspondencia

Shana Galindo

shanagalindo26@gmail.com

Recibido: 31/10/2017

Aprobado: 15/11/2017

Citar como: Galindo S, Aramburú $A$, Condori FJ, Gutierrez EL, Hijar G. Utilidad de las pruebas de detección de antígeno urinario para un diagnóstico rápido de legionelosis. Acta Med Peru. 2017;34(4):333-4

\author{
Shana Galindo 1,a, Adolfo Arambur ${ }^{41, b}$, Fredy J. Condori',c, Ericson L. Gutierrez ${ }^{1,2, d}$, \\ Gisely $\mathrm{Hijar}^{1, \mathrm{c}}$ \\ 1 Centro Nacional de Salud Pública, Instituto Nacional de Salud. Lima, Perú \\ 2 Facultad de Medicina, Universidad de San Martin de Porres. Lima, Perú. \\ a enfermera, b nutricionista, c biólogo, d médico
}

\section{Sr. Editor:}

La legionelosis (LD) es una enfermedad causada principalmente por la bacteria Legionella pneumophila (L. pneumophila), responsable del $2 \%$ al $15 \%$ de neumonías adquiridas en la comunidad a nivel mundial. L. pneumophila cuenta con 15 serogrupos, siendo el serogrupo 1 el causante de aproximadamente el $90 \%$ de los casos de LD ${ }^{[1]}$.

Presenta sintomatología respiratoria variable, desde afecciones leves a formas graves de neumonía potencialmente mortales. En el Perú, no se dispone de datos epidemiológicos sobre la incidencia de esta enfermedad ${ }^{[2]}$; a pesar que existen condiciones medio ambientales que podrían favorecer su crecimiento y propagación.

El estándar de referencia para el diagnóstico de LD es el aislamiento de la bacteria en cultivo de secreciones respiratorias. Esta prueba, aunque esencial en lugares con alta incidencia de $L$. pneumophila, puede demorar entre 3 a 12 días y presentar una baja sensibilidad. Asimismo, existen pruebas moleculares basadas en PCR en tiempo real que permiten identificar múltiples organismos causantes de neumonías atípicas como Chlamydia, Mycoplasma y Legionella, las cuales son más rápidas y sensibles que los métodos tradicionales ${ }^{[3]}$.

El Instituto Nacional de Salud de Perú (INS), como ente de referencia nacional en el diagnóstico de enfermedades transmisibles y no transmisibles, viene desarrollando una propuesta de desarrollo y validación de una prueba molecular basada en PCR, que contribuiría a mejorar el diagnostico etiológico de las neumonías atípicas (protocolo de investigación "Desarrollo y validación de la PCR multiplex en tiempo real para el diagnóstico molecular de neumonías atípicas en el INS"). Sin embargo, la implementación de estos métodos moleculares requiere de personal e instalaciones especializadas. Por tal motivo, las pruebas de detección de antígeno urinario (UAT) han surgido como alternativa, al no requerir métodos invasivos, ni equipos especializados y presentar un tiempo de respuesta corto, pudiendo mejorar el pronóstico de la enfermedad a través del inicio oportuno de tratamiento ${ }^{[4]}$.

En este contexto, realizamos una revisión de evidencias sobre la precisión diagnóstica de las pruebas UAT para $L D$, considerando el aislamiento en cultivo como estándar de referencia. Encontramos un metaanálisis de 32 estudios publicados entre los años 1966 y 2008 que reportó valores de sensibilidad de $74 \%$ y especificidad de $99 \%$ de las pruebas UAT para el diagnóstico de L. pneumophila serogrupo 1 , sin hallar diferencias entre los diferentes kits comerciales incluidos ${ }^{[5]}$. Cabe mencionar que dos estudios incluidos en esta revisión coincidieron en demostrar un pobre rendimiento de las pruebas UAT para detectar especies diferentes a L. pneumophila serogrupo 1. La calidad de la evidencia de los estudios incluidos fue baja.

Recientemente un estudio desarrollado en Estados Unidos ${ }^{[6]}$ reportó valores de sensibilidad del $92 \%$, así mismo, un estudio desarrollado en Canadá ${ }^{77]}$ reportó valores de sensibilidad de $87 \%$, especificidad de $94 \%$, valor predictivo positivo de $63,8 \%$ y valor predictivo negativo de $98,5 \%$, en ambos casos las muestras correspondieron a L. pneumophila serogrupo 1 . 
En conclusión, las pruebas UAT podrían ser útiles para realizar un diagnóstico rápido de legionelosis causada por L. pneumophila serogrupo 1, el cual es, en la mayoría de los casos, el agente causal de la enfermedad. Así mismo, es necesario precisar que estas pruebas no tienen utilidad para detectar infecciones causadas por serogrupos diferentes de L. pneumophila serogrupo 1. Debido a sus valores se sensibilidad (promedio del $80 \%$ ) y especificidad (97-100\%), un resultado negativo no descarta la infección por L. pneumophila serogrupo 1, por lo que se debe sospechar la enfermedad ante la presencia de síntomas sugerentes, sobre todo en áreas donde esta es prevalente.

Las pruebas UAT no deberían reemplazar al cultivo ni las pruebas moleculares en los laboratorios que cuenten con estos medios, ya que son útiles para realizar investigaciones epidemiológicas, estudios de sensibilidad frente a antimicrobianos, y verificar su concordancia con las pruebas UAT. Asimismo, se deben desarrollar más estudios prospectivos con adecuada calidad metodológica y que incluyan otros serogrupos de L. pneumophila.

Fuente de financiamiento: Instituto Nacional de Salud.

Conflictos de interés: Ninguno

\section{REFERENCIAS BIBLIOGRÁFICAS:}

1. Gea E. Legionelosis, ¿una nueva realidad en la República de Ecuador? Salud Uninorte. 2015;31(2):385-93.

2. Ministerio de Salud del Perú. Neumonía adquirida en la comunidad en adultos mayores. Bol Epidemiol (Lima). 2012;21(35):565-6.

3. Guillén R, Franco R, Franco L, Moraga P, Ojeda M, Russomando G. Detección por PCR múltiple en gérmenes atípicos en pacientes con neumonía adquirida en la comunidad que concurrieron al INERAM. Mem Inst Investig Cienc Salud. 2012;10(1):24-35.

4. Rivero L. Test de detección rápida de Legionella [Internet]. Madrid: Grupo de Patología infecciosa AEPap; 2014 [citado el 11 de agosto de 2017]. Disponible en: https://www.aepap.org/sites/default/ files/test_rapido_de_legionella.pdf

5. Shimada T, Yoshinori N, Jackson J, Miyashita J, Hayashino Y, Kamiya $\mathrm{T}$, et al. Systematic review and metaanalysis urinary antigen test for Legionellosis. Chest. 2009;136(6):1576-85.

6. Chen D, Procop G, Vogel S, Yen B, Richter S. Utility of PCR, culture, and antigen detection methods for diagnosis of Legionellosis. J Clin Microbiol. 2015;53(11):3474-7.

7. Peci A, Winter A, Gubbay J. Evaluation and comparison of multiple test methods, including real-time PCR, for Legionella detection in clinical specimens. Front Public Health. 2016;4:175.

\title{
Las ediciones anteriores de Acta Médica Peruana están disponibles en:
}

\author{
www.redalyc.org
}

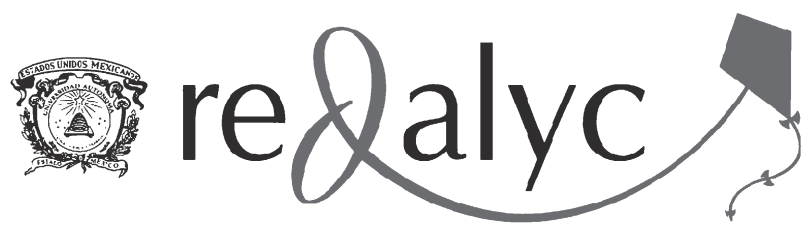

